\title{
O PROCESSO DE EXPANSÃO E INTERIORIZAÇÃO DAS UNIVERSIDADES FEDERAIS BRASILEIRAS E SEUS DESDOBRAMENTOS
}

\author{
THE EXPANSION AND INTERIORIZATION PROCESS OF BRAZILIAN FEDERAL UNIVERSITIES AND \\ THEIR DEVELOPMENTS
}

EL PROCESO DE EXPANSIÓN E INTERIORIZACIÓN DE LAS UNIVERSIDADES FEDERALES

BRASILEÑAS Y SUS DESARROLLOS

\begin{abstract}
Resumo: O texto analisa a recente expansão da rede de universidades federais brasileiras e indica que esse processo, ao fortalecer o modelo multicampi, contribuiu para a democratização do acesso ao ensino superior público e para o desenvolvimento regional em diversos sentidos, promovendo também condições para que a própria universidade reveja seus modelos institucionais, favorecendo a interdisciplinaridade e o diálogo do meio acadêmico com a sociedade. Em sentido contrário ao modelo gerencialista de gestão universitária, a atuação dos novos campi remete à discussão a respeito da universidade como bem público e do seu papel na redução das desigualdades sociais e na promoção do desenvolvimento humano.
\end{abstract}

Palavras-chave: Expansão do ensino superior. REUNI. Universidades Federais.

\begin{abstract}
The text analyzes the recent expansion of the network of Brazilian federal universities and indicates that this process, by strengthening the multicampi model, contributed to the democratization of access to public higher education and to regional development in several ways, also promoting conditions for the universities to review its institutional models, favoring interdisciplinarity and academia dialogue with society. Contrary to the managerialist canon of university management, the performance of the new campuses refers to the discussion about the university as a public good, and its role in reducing social inequalities and promoting human development.
\end{abstract}

Keywords: Brazilian Universities. Expansion of higher education. REUNI.

\footnotetext{
${ }^{1}$ Faculdade UnB Planaltina, Universidade de Brasília. Planaltina, Distrito Federal, Brasil.
} 
Resumen: El texto analiza la reciente expansión de la red de las universidades federales brasileñas e indica que este proceso, al fortalecer el modelo multicampi, contribuyó a la democratización del acceso a la educación superior pública y al desarrollo regional de varias maneras, además de promover las condiciones para que la propia universidad revise sus modelos institucionales, promoviendo la interdisciplinariedad y el diálogo entre el mundo académico y la sociedad. Contrario al modelo de gestión empresarial de la universidad, el desempeño de los nuevos campus remite a la discusión sobre la universidad como un bien público, y su papel en la reducción de las desigualdades sociales y la promoción del desarrollo humano.

Palabras clave: Expansión de la educación superior. REUNI. Universidades Federales.

\section{INTRODUÇÃO}

O ensino superior iniciou-se tardiamente no Brasil em comparação às demais colônias europeias nas Américas. Enquanto que em fins do século XVII havia doze universidades nas colônias espanholas da América Latina, de Santo Domingo a Córdoba, somente na primeira metade do século XIX foram implantadas no Brasil as primeiras Faculdades de Medicina do Rio de Janeiro e da Bahia (TRINDADE, 2012). A partir de então surgiram outras Escolas Superiores ou Faculdades isoladas e disciplinares, como Escolas de Agronomia, de Enfermagem, de Engenharia, e Faculdades de Direito, Medicina, Pedagogia entre outras, em diversas regiões do país, consolidando um modelo de educação superior sem universidades (SEABRA SANTOS; ALMEIDA FILHO, 2012). Apenas nas primeiras décadas do século XX foram instaladas as primeiras universidades, por iniciativas locais em alguns estados da federação e, somente a partir da década de 1940, iniciou-se um processo de federalização das mesmas.

Dos primeiros campi ${ }^{2}$ das universidades federais estabelecidos nas décadas de 1950 e 1960, seguiu-se um crescimento lento até a década de 1980, quando foram criados novos campi, sobretudo na região Norte. A década de 1990 foi marcada por drástica redução no investimento nas universidades públicas e exponencial crescimento das instituições privadas de ensino superior (GONÇALVES, 2008; DUTRA, 2012; TRAINA-CHACON; CALDERÓN, 2015). A partir dos primeiros anos do século XXI, houve uma nova fase de crescimento do ensino superior público em todas as regiões, aumentando em mais que o dobro o número de campi universitários existentes no país.

\footnotetext{
${ }^{2}$ Plural de campus, que é o local onde se situa a instituição universitária, também chamado de cidade universitária ou pólo universitário. Quando a universidade tem mais de um campus é chamada de multicampi.
} 
A principal política pública responsável por esse crescimento foi o Programa de Reestruturação e Expansão das Universidades Federais (REUNI), implantado no governo Lula (20032010) a partir de 2007, tendo havido também uma primeira fase de expansão do Ensino Superior Federal, denominada Expansão I, que compreendeu os anos de 2003 a 2007 (BARROS, 2015), e outra fase de significativa criação de novos campi, entre os anos de 2011 a 2015, no governo de Dilma Roussef. O REUNI visou o aumento de vagas e também a expansão da rede universitária, sobretudo na perspectiva de atender o interior do país, dado que a maioria das universidades federais se encontrava nas capitais e em cidades de maior porte. Segundo dados do Ministério da Educação, o processo de interiorização dos campi das universidades federais brasileiras ampliou o número de municípios atendidos pelas universidades de 114 em 2003 para 237 até o final de 2011, e resultou em um aumento de aproximadamente $70 \%$ das matrículas presenciais na rede federal (BRASIL, 2017).

O debate em torno da expansão do ensino superior no Brasil nos governos Lula e Dilma tem se concentrado na análise do número de instituições e de matrículas nos cursos de graduação nos sistemas público e privado (MANCEBO, 2015; BARROS, 2015; TRAINA-CHACON; CALDERÓN, 2015). Nesse artigo o processo de interiorização das universidades federais na última década é analisado em função do impacto, real e potencial, da instalação dos novos campi nos contextos das universidades e da sociedade, a partir de referências bibliográficas, dados obtidos dos sítios das universidades federais na internet e observação de casos, marcadamente o da expansão da Universidade de Brasília, iniciada em 2006, concomitante à implementação do REUNI.

\section{METODOLOGIA}

Trata-se de uma pesquisa documental de cunho exploratório. A lista das universidades federais brasileiras foi obtida a partir do sítio do Ministério da Educação na internet, sobretudo o relativo ao Programa de Reestruturação e Expansão das Universidades Federais (REUNI) e do sítio da Associação Nacional dos Dirigentes das Instituições Federais de Ensino Superior (Andifes).

Os dados sobre o número de campi, cidades sede e histórico de cada campus foram obtidos a partir dos sítios na internet de cada uma das universidades federais nas cinco regiões geopolíticas brasileiras: norte, nordeste, centro-oeste, sudeste e sul. Como se trata de um estudo da 
interiorização das universidades federais, nessa pesquisa foram considerados campi os casos de unidades acadêmicas situadas em cidades distintas do campus principal, devidamente identificadas no sítio da universidade por meio dos termos campus ou unidade acadêmica e contendo link de acesso para os mesmos, em sítios específicos ou apresentando imagens e informações dos campi. De fato, alguns campi não dispunham de sítios próprios, sendo apenas referenciados no portal da universidade com a apresentação de pequeno texto com fotos. Outros campi dispunham de sítio próprio, mas que continha apenas informações da gestão do cotidiano (matrículas, informes etc.) sem referências a data de criação ou outros aspectos da história do campus. Nesses casos, foi enviada mensagem eletrônica ao campus solicitando a data de inauguração do mesmo. Contudo, não foi possível precisar a data de inauguração de 22 dos campi pesquisados.

Para fins desse estudo, as datas indicadas da criação das universidades são geralmente a data do decreto que as federaliza como universidades. Desse modo, a data de existência das instituições pode ser muito mais antiga (por volta das primeiras décadas do século XX) do que a data em que passou a ter o status de universidade federal, que em muitos casos ocorreu a partir de fusões entre instituições distintas. Foram mantidas as datas originais apenas nos casos de instituições que foram criadas com a nomenclatura de Universidade e que não sofreram fusões com outras até o presente, apenas mudando de nomenclatura para Universidade Federal. Esses são os casos da UF Rural de Pernambuco, UF do Rio de Janeiro, UF da Bahia, UF de Minas Gerais, entre outras. $\mathrm{O}$ ano de 2005 foi considerado o ano de corte para definir os períodos antes e depois das políticas de expansão das universidades federais em análise.

\section{O PROCESSO DE EXPANSÃO E INTERIORIZAÇÃO DAS UNIVERSIDADES FEDERAIS}

Foi identificado um total de 267 campi pertencentes a 63 universidades, sendo a região Sudeste a que abrigou mais universidades e a Nordeste o maior número de campi. As universidades apresentaram em média cinco campi, sem diferenças significativas entre as regiões, mas com grande variação entre as universidades (Tabela 1). Apenas nove universidades apresentaram um campus único. A Universidade Tecnológica Federal do Paraná apresentou o maior número de campi, totalizando treze. 
A análise dos períodos antes e depois da expansão indica que houve crescimento significativo no número de universidades federais, que aumentou em dezessete novas instituições. Entretanto, o principal impacto para a interiorização do ensino superior público foi o expressivo aumento no número de campi em todas as regiões do país (figura 1), revelando que a política atingiu as universidades de forma a induzir a construção de um modelo universitário multicampi, anteriormente existente apenas em parte das universidades federais (figura 2). As novas universidades criadas também tiveram tendência a adotar o modelo multicampi.

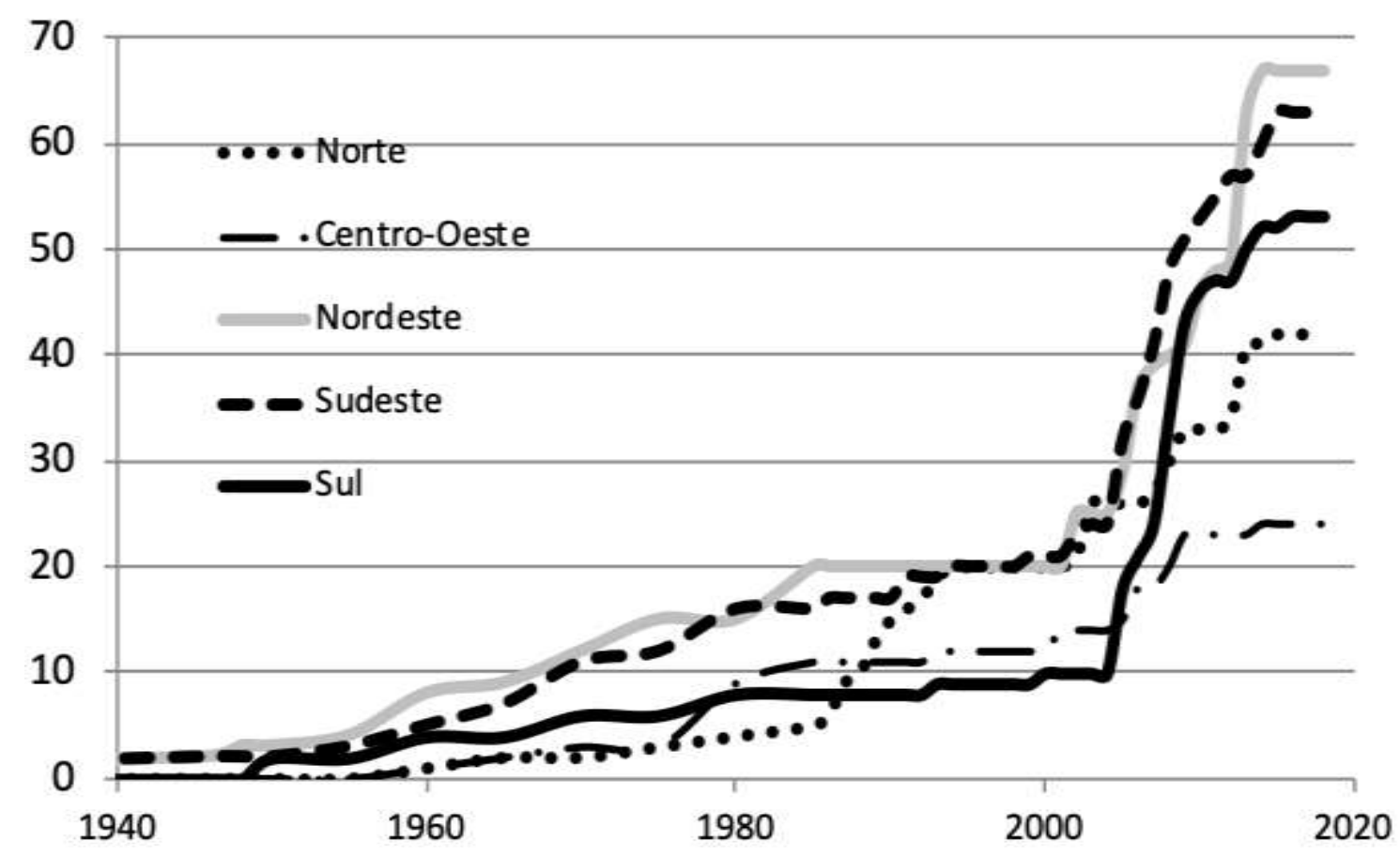

Figura 1 - Número de campi de universidades federais por região ao longo dos anos. Fonte: Elaboração do autor.

Tabela 1 - Totais de campi de universidades federais nas regiões estudadas.

\begin{tabular}{ccccccc}
\hline Região & $\begin{array}{c}\text { Total de } \\
\text { Universidades }\end{array}$ & $\begin{array}{c}\text { Total de } \\
\text { campi }\end{array}$ & $\begin{array}{c}\text { Média de } \\
\text { campi por } \\
\text { Universidade }\end{array}$ & DP & $\begin{array}{c}\text { Mínimo de } \\
\text { campi por } \\
\text { Universidade }\end{array}$ & $\begin{array}{c}\text { Máximo de } \\
\text { campi por } \\
\text { Universidade }\end{array}$ \\
\hline Norte & 10 & 50 & 5 & 3,4 & 1 & 12 \\
Centro-oeste & 5 & 24 & 4,8 & 3,3 & 1 & 10 \\
Nordeste & 18 & 75 & 4,2 & 1,9 & 1 & 9 \\
Sudeste & 19 & 63 & 3,3 & 1,9 & 1 & 9 \\
Sul & 11 & 55 & 5 & 3,8 & 1 & 13 \\
\hline \multicolumn{7}{r}{ Fonte: Elaboração do autor. }
\end{tabular}




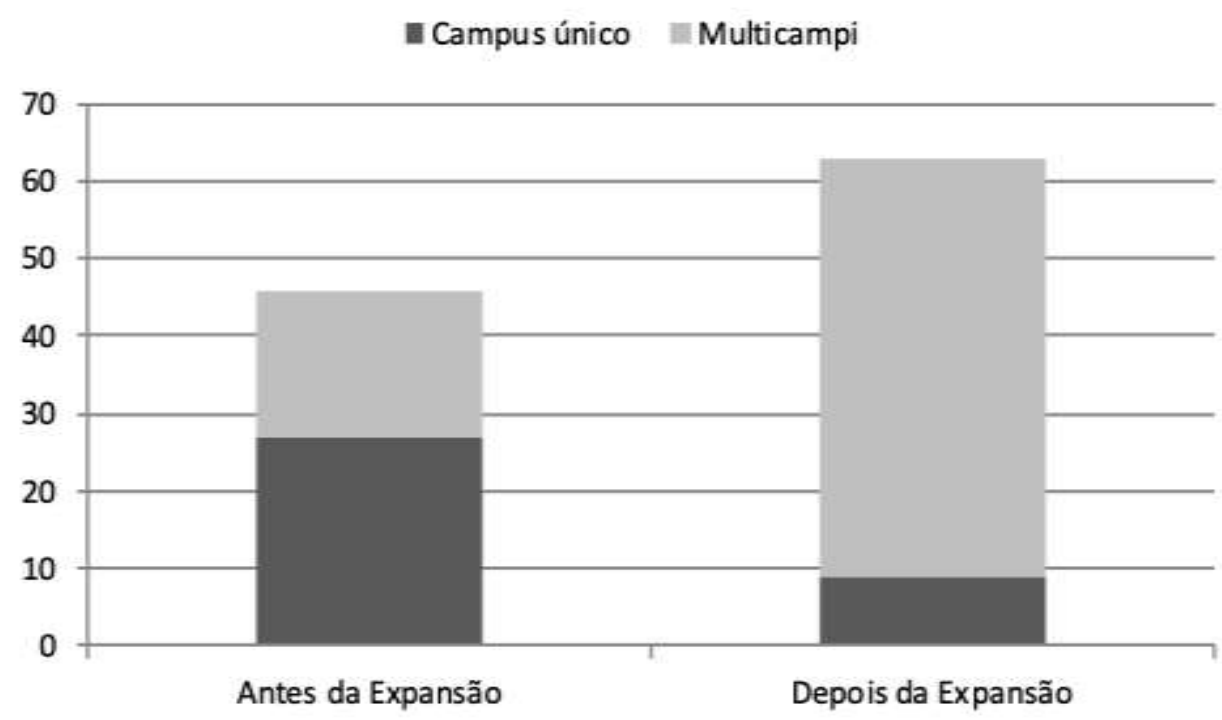

Figura 2 - Número de Universidades Federais com campus único ou multicampi antes e depois da expansão. Fonte: Elaboração do autor.

As políticas de expansão da rede de universidades federais brasileiras contribuíram para a interiorização dos campi e suas consequências para a democratização do acesso ao ensino superior público a partir das seguintes ações: (i) a criação de novas universidades concebidas a partir de novas propostas de organização e estrutura acadêmica; (ii) a criação de novas universidades concebidas a partir do desmembramento de campi de universidades pré-existentes; (iii) o estímulo à criação de novos campi das universidades pré-existentes; (iv) a viabilização de diversos campi oriundos de processos de expansão anteriores e autônomos das universidades, que não puderam desenvolver-se integralmente como unidades acadêmicas em função da carência de recursos e de pessoal.

No caso das novas universidades, foi priorizado o atendimento a regiões não atendidas pela rede federal, como são os casos da Universidade Federal do Sul da Bahia (UFSB), Universidade Federal do Oeste da Bahia (UFOB), e Universidade Federal da Fronteira Sul (UFFS), Universidade Federal do Pampa (UNIPAMPA) entre outras. Existem também casos em que instituições federais passaram a constituir uma nova universidade, como é o caso da UF Grande Dourados que foi anteriormente um campus da UF Mato Grosso do Sul (UFMS), ou da Universidade Federal do Sul e Sudeste do Pará (UNIFESSPA), anteriormente parte da Universidade Federal do Pará (UFPA). Cabe destacar dois projetos estratégicos de colocar o ensino superior a serviço da internacionalização em 
importantes contextos geopolíticos: são os casos da Universidade de Integração Internacional de Lusofonia Afro-Brasileira (UNILAB), instalada no Ceará, e da Universidade Federal da Integração Latino-Americana (UNILA), instalada em Foz do Iguaçu, estado do Paraná.

Já no caso dos novos campi, o REUNI estimulou as universidades a modificar a sua estrutura para um contexto multicampi. E nos casos em que a instituição já era multicampi ou tinha projeto de expansão, foi determinante na viabilização desses processos desencadeados pelas universidades por iniciativa própria, mas que, em muitos casos, foram afetados por dificuldades orçamentárias e de pessoal. Dos casos analisados nesse estudo, alguns campi existiam antes do REUNI de forma muito incipiente como, por exemplo, o campus da UFG em Jataí, criado em 1980, e que contava até 2004 com 5 servidores e 43 docentes, funcionando por meio de convênio com o estado de Goiás e a prefeitura de Jataí. Atualmente, 400 professores e 100 servidores técnico-administrativos do quadro efetivo da universidade dão suporte às atividades desenvolvidas no campus, que em 2018 deu origem à Universidade Federal de Jataí (UFJ). O campus de Planaltina foi o primeiro da expansão da Universidade de Brasília, inaugurado antes do REUNI, em 2006, mas foi a sua inclusão no programa que possibilitou as condições orçamentárias e de pessoal necessárias à sua efetiva implantação (BIZERRIL; LE GUERROUÉ, 2012). Outro exemplo é o do campus da Universidade Federal de Tocantins (UFT) em Tocantinópolis, que foi inaugurado em 1990 por decreto estadual como campus da UNITINS e que passou a fazer parte da UFT em 2003 com a criação formal da universidade, evitando, assim, o processo de privatização que avançava na instituição. Fica patente a importância da federalização em fortalecer e agregar as iniciativas estaduais e municipais de educação superior garantindo sua condição de instituição pública e gratuita.

\section{OS IMPACTOS DOS NOVOS CAMPI NO DESENVOLVIMENTO LOCAL E REGIONAL}

Vários estudos têm procurado avaliar os impactos da expansão do ensino superior público no Brasil. O impacto mais perceptível pela sociedade, e aquele que recebe maior atenção dos pesquisadores e também da mídia, é o aumento no número de vagas para os cursos de graduação, mas a situação pode ser analisada por vários outros aspectos (ROLIM; SERRA, 2009; BRITO, 2014). Por exemplo, do ponto de vista econômico, uma região que recebe um campus universitário se beneficia já no curto prazo pelo investimento federal no município em termos dos salários e gastos da universidade em seus processos de instalação e manutenção, assim como no movimento na 
economia local causado pela vinda de estudantes de outras regiões. De fato, ao investir financeiramente nas universidades, o governo federal garantiu a execução de obras de relevante porte realizadas concomitantemente em diversos locais do país, que poderiam ter tido outras destinações caso os recursos tivessem sido repassados aos municípios. Outro efeito econômico de médio e longo prazo relaciona-se aos egressos e ao impacto da qualificação e da inovação na economia local, também gerados pela atenção com a qual os temas locais passam a ser tratados por parte dos projetos de pesquisa e de extensão desenvolvidos por essas universidades.

Em estudo sobre os impactos econômicos dos Institutos Federais nas economias dos municípios brasileiros, Faveri et al. (2018) encontraram impactos mais expressivos nos municípios de menor porte. No entanto, estudos dessa natureza se fazem necessários também no que diz respeito aos campi das universidades federais. Quanto aos impactos da extensão universitária, é reconhecida a tradição das universidades latino-americanas em ter a extensão como um de seus principais pilares (MORA; SERRA; VIEIRA, 2017), aproximando-as daquela que é chamada tanto na Europa quanto na América do Norte como a missão cívica da universidade, a de se envolver com suas comunidades, pesquisando e produzindo soluções para os problemas locais significativos (ĆULUM, 2014). Aparentemente, devido a sua proximidade real com as comunidades locais e da presença massiva de seus membros no interior da universidade, os campi do interior são mais provocados no sentido de construir ações de extensão mais afinadas com os interesses e demandas da comunidade. Na Universidade de Brasília, em poucos anos, os novos campi, situados na periferia da capital, se tornaram as unidades acadêmicas com maior número de ações de extensão em andamento.

Outros impactos de maior dificuldade de mensuração, mas determinantes para o desenvolvimento regional, estão ligados ao desenvolvimento humano. A disseminação da cultura universitária, que agrega valores como a democracia, a liberdade, a responsabilidade social, a ética, o pensamento científico e crítico, traz importantes contribuições regionalmente nos âmbitos político, social e cultural. Ainda que todo o sistema de ensino superior brasileiro deva atuar no sentido do atendimento a essa demanda, diversos fatores - como a estrutura acadêmica e administrativa mais diversificada e democrática, o apoio à permanente qualificação profissional e internacionalização, o regime de trabalho que possibilita condições para a realização de projetos de pesquisa e extensão, além da própria história de autonomia e vocação dessas instituições (LEHER, 
2019; NÓVOA, 2019) - fortalecem a ideia de que as universidades públicas, com destaque para as federais, estejam mais bem dotadas das condições para cumprir esse papel.

É papel intrínseco da universidade a livre promoção do debate e da análise crítica a respeito de tudo que se relacione à ciência e à sociedade, pois esse é o modus operandi da produção do conhecimento e da formação de sujeitos reflexivos, que é a razão primária da existência dessas instituições. Ao longo das últimas décadas, diversos pensadores (RIBEIRO, 1986; SEABRA SANTOS; ALMEIDA FILHO, 2012; DIAS-SOBRINHO, 2016; CHAUÍ, 2018; NÓVOA, 2014, 2019; LEHER, 2019) vêm reiterando essa característica da universidade forjada ao longo de sua história milenar, ao mesmo tempo em que rejeitam a redução da atividade da universidade à mera formação de mão-de-obra para atender os interesses do mercado ou do Estado.

Estudos têm indicado que os novos campi tendem a receber, em sua maioria, estudantes da região de influência do campus, o que aumenta as possibilidades dos impactos positivos relatados acima atingirem comunidades antes não contempladas com o ensino superior público. Fica evidente que se o mesmo investimento financeiro e de recursos humanos tivesse sido feito de forma concentrada nos campi centrais das Universidades Federais, ainda que houvesse aumento no número de matrículas, o impacto estaria longe de ser o mesmo (BRITO, 2014), pois aspectos como acesso e permanência dos estudantes, impacto econômico regional e relação com a comunidade local nas dimensões cultural, social e política não teriam atingido as microrregiões que receberam os novos campi.

\section{AS CONSEQUÊNCIAS DA EXPANSÃO PARA AS UNIVERSIDADES}

Diversos autores lusófonos que discutem os desafios das universidades neste século (SANTOS; ALMEIDA FILHO, 2009; MELLO, 2011; SEABRA SANTOS; ALMEIDA-FILHO, 2012; NÓVOA, 2014; PEDROSA, 2014; DIAS-SOBRINHO, 2016, entre outros) têm remetido às universidades demandas contemporâneas dentre as quais destacam-se: (i) projeção científica internacional; (ii) produção de conhecimento significativo; (iii) capacidade de dialogar com outros saberes e setores da sociedade; (iv) transferência tecnológica e atuação no setor produtivo e na economia; (v) formação profissional qualificada; (vi) formação cidadã e de lideranças; (vii) renovação da gestão pública; (viii) renovação de práticas pedagógicas e do Ensino Superior; (ix) redução das 
desigualdades sociais; $(x)$ responsabilidade social e envolvimento com as questões locais e nacionais; (xi) promoção da sustentabilidade. Enfim, espera-se cada vez mais que as universidades assumam papel de centralidade no processo de transformação da sociedade para patamares civilizatórios mais elevados.

A longa história da universidade, sua estrutura por vezes conservadora e uma crescente cultura individualista e de competitividade têm sido consideradas como causadoras das resistências às mudanças necessárias a fim de que a universidade deixe o isolamento da condição de Torre de Marfim, de guardiã do saber científico, porém desconectada da realidade, e busque atender a essas demandas contemporâneas, se aproximando das necessidades da sociedade (ĆULUM, 2014; CHAUÍ, 2018).

A possibilidade de criação de novas universidades e campi tem promovido as condições para que a comunidade universitária fortaleça seu envolvimento com o projeto de universidade como bem público, e avance em seus modelos institucionais e de avaliação da qualidade, favorecendo, sobretudo, a interdisciplinaridade, a sustentabilidade e o diálogo do meio acadêmico com a realidade das comunidades, o que, de fato, pode ser exemplificado em diversos casos, como o da Universidade Federal do ABC (TAVARES; GOMES, 2018), e outros identificados nos sítios das universidades como nos exemplos da Universidade Federal da Integração Latino-americana (UNILA) e do campus Litoral da Universidade Federal do Paraná:

\begin{abstract}
"A missão institucional da UNILA é a de formar recursos humanos aptos a contribuir com a integração latino-americana, com o desenvolvimento regional e com o intercâmbio cultural, científico e educacional da América Latina, especialmente no Mercado Comum do Sul (Mercosul)." 3

"A proposta pedagógica da UFPR Litoral é baseada em projetos e desenvolvida junto às comunidades locais, buscando contribuir decisivamente para o desenvolvimento científico, econômico, ecológico e cultural. Isso propicia uma forte interação entre a comunidade da UFPR Litoral e a comunidade litorânea na construção de um novo ciclo de desenvolvimento regional." ${ }^{4}$
\end{abstract}

Paralelamente a isso, a partir do REUNI, houve significativa mudança do perfil dos discentes, agregando parcelas da população antes pouco representadas nas universidades públicas (NIEROTKA; TREVISOL, 2016; TAVARES; GOMES, 2018), como indígenas, negros, moradores da

\footnotetext{
${ }^{3}$ Sobre a UNILA. Disponível em: https://portal.unila.edu.br/institucional. Acesso em: 04 Jun.2020.

${ }^{4}$ Educação por projetos. Disponível em: http://www.litoral.ufpr.br/portal/ufpr-litoral/projetos/. Acesso em: 04 Jun. 2020.
} 
periferia, povos do campo, LGBTQI+ e outros, na grande maioria das vezes compondo a primeira geração da família a obter um diploma do ensino superior. Esse fenômeno ampliou a diversidade sociocultural da comunidade universitária, trazendo novos desafios antes ignorados pelas instituições que, apesar de públicas, na prática atendiam majoritariamente a uma restrita parcela da elite e da classe média do país.

Lidar com essa nova realidade, que na verdade é a realidade social do Brasil, significa trazer a universidade para um local de relevância social estratégica para o país, fato ainda não compreendido pela maioria da população, que justamente por isso tende a concordar com propostas governamentais de cortes de verbas das universidades públicas ou de implantação de modelos de gestão travestidos de inovadores, mas que na prática submetem a universidade aos interesses do mercado a partir de uma lógica empresarial, competitiva e privatista, que resulta em uma visão estreita do trabalho universitário (LIMA, 2012; NÓVOA, 2019). De fato, os padrões hegemônicos de avaliação do ensino superior, em quase sua totalidade impostos pelos países economicamente mais desenvolvidos e menos desiguais socialmente que o Brasil, não consideram os fatores culturais e de desenvolvimento humano e regional e fixam-se na produção científica tradicional, expressas pelas publicações indexadas, e nos valores de interesse do mercado. Tomando o exemplo dos principais rankings internacionais, verificaremos que concentram sua pontuação na reputação da universidade no meio acadêmico ou entre os empregadores, mas não consideram a avaliação que as comunidades local ou regionalmente fazem da instituição. Os rankings consideram as citações da produção científica por docente, mas não pontuam projetos de desenvolvimento e ações de extensão que conferem relevância da universidade junto à sociedade. Finalmente, os rankings consideram a proporção entre o número de estudantes e docentes como indicador da qualidade do ensino, mas não avaliam a composição da população discente, ou seja, desconsideram a equidade, a diversidade e as políticas de apoio à permanência dos estudantes menos favorecidos como indicadores do compromisso da universidade em combater a desigualdade social. Enfim, de fato esses instrumentos de avaliação possibilitam analisar as instituições a partir de distintos indicadores. No entanto, há forte tendência de estarem ligados à formação profissional por área do conhecimento, enquanto quase nenhum considera a universidade integralmente e seu desempenho no âmbito dos desafios que se apresentam às instituições de educação superior na contemporaneidade, sobretudo nos países em desenvolvimento. A exemplo de autores como Nóvoa (2019), Santos e Almeida-Filho (2009) e outros, Thiengo, Bianchetti e De Mare (2018) indicam 
os perigos da difusão do modelo de Universidades de Classe Mundial (UCM) para os países emergentes e para a instituição universitária de modo geral:

Portanto, o que os rankings têm induzido ao difundirem o modelo de UCM e sua "ideologia da excelência" apontam para o aprofundamento da diferenciação inter e intrainstitucional, bem como o fortalecimento de concepções de universidade e ciência cada vez mais pragmáticas e utilitárias, conspirando ou subvertendo o próprio conceito histórico de universitas (THIENGO; BIANCHETTI; DE MARE, 2018, p.1054).

\section{CONSIDERAÇÕES FINAIS}

A universidade pública é uma instituição imprescindível para a sociedade porque, diferentemente de uma organização privada autocentrada, tem a sociedade como sua referência (DIAS-SOBRINHO, 2016). O exercício da gestão democrática, aliado ao pensamento científico e crítico e à liberdade de expressão, confere às universidades a condição, cada vez mais essencial, de atuarem como consciência crítica da sociedade e do Estado, problematizando o autoritarismo e o senso comum irracionalista (SCHÜTZ; FUCHS; COSTA, 2020). Daí porque "governos com pretensão autocrática, igrejas fundamentalistas, grupos econômicos hostis ao desenvolvimento social, agrupamentos corporativos particularistas, forças políticas conservadoras em geral não possuem apreço à autonomia universitária" (LEHER, 2019, p.222).

A disseminação desse perfil de instituição pelo país afora indica o potencial que os novos campi das universidades federais têm para promover, se não uma considerável revolução social, ao menos a resistência a tempos de crescimento do autoritarismo e ataques à ciência e à razão. $A$ ampliação do acesso ao ensino superior, a mudança do perfil do estudante universitário, o aumento da produção de conhecimento sobre fatos e regiões antes ignoradas pela academia, oxigenaram a cultura universitária e aproximaram a universidade da sociedade, fortalecendo a sua vocação de agente transformador da realidade brasileira.

Por outro lado, a simples existência do campus interiorizado não garante o pleno êxito do seu papel no desenvolvimento local e regional. A diversidade de instituições, conjunturas políticas, culturas universitárias, contextos locais e perfis humanos que compõem as equipes de cada campus deve ser objeto de futuras investigações que poderão ampliar a compreensão a respeito do processo de expansão das universidades federais no Brasil. 
O entendimento das universidades federais como instituições estratégicas ao desenvolvimento, tanto humano quanto regional é atualmente uma necessidade premente à sociedade brasileira. No caso dos campi instalados na última década, é essencial que estudos subsidiem a criação de políticas de apoio de longo prazo à manutenção e fortalecimento dos mesmos de modo a ampliar os benefícios potenciais dessas instituições para o país.

\section{REFERÊNCIAS}

BARROS, A.S.X. Expansão da Educação Superior no Brasil: limites e possibilidades. Educ.Soc., Campinas, v. 36, n. 131, p. 361-390, 2015.

BIZERRIL, M.X.A.; LE GUERROUÉ, J.L. FUP: a construção coletiva de um campus interdisciplinar. In: Saraiva, R.C.F. \& Diniz, J.D.A.S. (Org.). Universidade de Brasília: trajetória da expansão nos 50 anos. $1^{a}$ ed. Brasília: Decanato de Extensão, p. 23-30, 2012.

BRASIL. Ministério da Educação. REUNI - Programa de Reestruturação e Expansão das Universidades Federais. Disponível em: http://reuni.mec.gov.br. Acesso em: 25 jul. 2017.

BRITO, L.C. A importância dos estudos sobre interiorização da universidade e reestruturação territorial. Espaço e Economia - Revista Brasileira de Geografia Econômica, v. 2, n. 4, 2014. Disponível em: https://espacoeconomia.revues.org/802

CHAUI, M. Em defesa da educação pública, gratuita e democrática. Belo Horizonte: Editora Autêntica, 2018.

ĆULUM, B. Croatian academics and university civic mission integration: possibilities and constraints. In: BRANKOVIĆ, J. et al. (Eds.). Global challenges, local responses in higher education: the contemporary issues in national and comparative perspective. Rotterdam: Sense Publishers, 2014. p. 59-78.

DIAS SOBRINHO, J. Autonomia, formação e responsabilidade social: finalidades essenciais da universidade. Revista FORGES - Fórum da Gestão do Ensino Superior nos Países e Regiões de Língua Portuguesa, v. 4, n. 2, p. 13-30, 2016.

DUTRA, N.L.L. A expansão do ensino superior privado a partir de 1990: limites e possibilidades. Artificios, Revista do Difere, v. 2, n. 4, 2012.

FAVERI, D.B.; PETTERINI, F.C.; BARBOSA, M.P. Uma avaliação do impacto da política de expansão dos Institutos Federais nas economias dos municípios brasileiros. Planejamento e Políticas Públicas, n. 50, p. 125-147, 2018.

GONÇALVES, S.A. Estado e expansão do ensino superior privado no Brasil: uma análise institucional dos anos de 1990. Educar, Curitiba, n. 31, p. 91-111, 2008. 
LEHER, R. Autonomia universitária e liberdade acadêmica. Revista Contemporânea de Educação, v. 14, n. 29, p.209-226, 2019.

LIMA, L.C. Patterns of institutional management: democratization, autonomy and the managerialist canon. In: NEAVE, G., AMARAL, A. (Eds.), Higher Education in Portugal 1974-2009: a Nation, a Generation. CIPES/Springer, Porto, pp. 287e307. 2012.

MANCEBO, D. Educação superior no Brasil: expansão e tendências (1995-2014). 37ạ Reunião Nacional da ANPEd, Florianópolis: UFSC, 2015.

MELLO, A.F. Globalização, sociedade do conhecimento e educação superior: os sinais de Bolonha e os desafios do Brasil e da América Latina. Brasília: Editora UnB, 2011.

MORA, J.G.; SERRA, M.A.; VIEIRA, M.J. Social Engagement in Latin American Universities. Higher Education Policy, 2017. Doi:10.1057/s41307-017-0069-1

NIEROTKA, R.L.; TREVISOL, J.V. Os jovens das camadas populares na universidade pública: acesso e permanência. R. Katál., Florianópolis, v. 19, n. 1, p. 22-32, 2016.

NÓVOA, A. Em busca da liberdade nas universidades: para que serve a investigação em educação? Revista Lusófona de Educação, n. 28, p.11-21, 2014.

NÓVOA, A. O futuro da universidade: o maior risco é não arriscar. Revista Contemporânea de Educação, v.14, n.29, p.54-70, 2019.

PEDROSA, J. Autonomy and Accountability in University Governance. In: BERGAN, S. et al.(ed.). Leadership and Governance In Higher Education, v. 1, Berlin: Raabe Academic Publishers, 2014, p.23-39.

RIBEIRO, D. Universidade para quê? Brasília: Editora Universidade de Brasília, 1986.

ROLIM, C.; SERRA, M. Instituições de Ensino Superior e Desenvolvimento Regional: O Caso da Região Norte do Paraná. Revista de Economia, v. 35, n. 3 (ano 33), p. 87-102, set./dez, 2009.

SANTOS, B.S.; ALMEIDA FILHO, N. A Universidade no Século XXI: Para uma Universidade Nova. Coimbra: Edições Almedina, 2009.

SCHÜTZ, J.A.; FUCHS, C.; COSTA, C.O. Universidade, pesquisa e docência: reflexões críticas sobre os abusos do atual governo. Rev. Tempos Espaços Educ., v.13, n. 32, e-12530, 2020.

SEABRA SANTOS, F.; ALMEIDA FILHO, N. A quarta missão da Universidade: internacionalização universitária na sociedade do conhecimento. Brasília: EdUnB; Coimbra: Imprensa da Universidade de Coimbra, 2012.

TAVARES, M.; GOMES, S. Fundamentos epistemológicos da matriz institucional dos novos modelos de educação superior no Brasil: uma abordagem qualitativa dos documentos Institucionais da Universidade Federal do ABC. Educ. Soc., Campinas, v. 39, n. 144, p. 634-651, 2018. 
THIENGO, L.C.; BIANCHETTI, L; DE MARE, C.L. Rankings acadêmicos e universidades de classe mundial: relações, desdobramentos e tendências. Educ. Soc., Campinas, v. 39, n. 145, p. 1041-1058, 2018.

TRAINA-CHACON, J.M.; CALDERÓN, A.I. A expansão da educação superior privada no Brasil: do governo de FHC ao governo de Lula. Revista Iberoamericana de Educación Superior (RIES), México, UNAM-IISUE/Universia, v. 6, n. 17, p. 78-100, 2015.

TRINDADE, H. Por um novo projeto universitário: da "Universidade em ruínas" à "Universidade Emancipatória". In: SOUSA JÚNIOR, J.G.(Org.). Da Universidade necessária à Universidade emancipatória. Brasília: Editora UnB, 2012, p.89-142.

\section{SOBRE O AUTOR}

\section{Marcelo Ximenes Aguiar Bizerril}

Doutor em Ecologia, Universidade de Brasília (UnB); Faculdade UnB Planaltina, Universidade de Brasília Brasil; Programa de Pós-Graduação em Educação em Ciências e Programa de Pós-Graduação em Meio Ambiente e Desenvolvimento Rural. E-mail: bizerril@unb.br

ORCID: https://orcid.org/0000-0002-2993-155X

Recebido em: 20 de abril de 2020 Aprovado em: 08 de junho de 2020 Publicado em: 06 de julho de 2020 